\title{
Rhetoric and Meaning in Poetry: The Case of Zambia
}

\author{
Moffat Moyo \\ University of Zambia, Lusaka, Zambia
}

\begin{abstract}
This paper aims at showing how rhetoric and meaning in Zambian poetry interact. The work analyses the definition of poetry and gives the understanding that poetry is an artistic use of language that employs figurative language for maximum effect. The work also analyses rhetoric and concludes that the sole aim of rhetoric is to persuade the audience. The use of this rhetoric is later identified as a preoccupation of most poets. After studying a number of rhetorical devices used in poetry, the work has studied selected Zambian poems and focussed on the use of rhyme and alliteration in the poems. It has been shown that there is much use of rhyme but with limited use of alliteration. In both cases, the use is not so much to the contribution to the meaning in the poetry. The poets usually use these devices for the sake of beauty and not meaning. The paper therefore suggests that poets could undergo some formal training in composition while the art is also taught to the young while in their early years in schools.
\end{abstract}

Keywords: rhetoric, meaning, Zambian poetry, figurative language

\section{Introduction}

Poetry is that branch of literature which is related to man's deepest concerns. It is marked by rhythm and cadence, repetition, onomatopoeia, alliteration and other acoustic or visual images (Mtonga, 2008). These devices mark poetry as an art form that uses devices of rhetoric. According to Horace, the aim of a poet is either to instruct or to delight a reader, and preferably to do both. The poet's aim, therefore, will be to present beauty and hence delight his reader in his work (Abrams, 1999). This paper examines the use of rhetoric in poetry and how rhetoric and meaning marry in poetry. The paper begins by defining poetry and discussing the meaning brought out by the various definitions employed. The paper proceeds to defining rhetoric and later discussing how rhetoric is used in poetry. To show how rhetoric is used in poetry, the paper will exploit rhetoric devises that poets use. The next part will view the association between rhetoric and meaning in Zambian poetry and finally suggest areas needing further research.

\section{Poetry}

Poetry is a literary genre that is different from prose and drama in that it is characterised by the rhythmical qualities of language. The fundamental nature of poetry is compression, economy and force as opposed to the expansive and logic of prose (Roberts \& Jacobs, 2007). The idea that poetry is compressed can translate into it being seen as an art form that is also condensed. This is because, as opposed to prose that occupies a much larger space, poetry occupies a much smaller space. Economy, as with compression, refers to the use of minimal words

Moffat Moyo, lecturer, Department of Literature and Languages, University of Zambia. 
to send a message across. The authors seem to imply that poetry thrives on the use of few words to say a lot. And finally, talking about force, a poem, as can be picked from Emily Dickinson's (1830-1886) observation, quoted by the above source, is very powerful in that it has a huge impact on its audience's emotion. Dickinson said that if she was reading a book and found that it made

My whole body so cold that no fire ever can warm me I know that is poetry. If I feel physically as if the top of my head were taken off, I know that is poetry. (Roberts \& Jacobs, 2007, p. 1109)

Dickinson here suggests that a poem is supposed to be different from ordinary use of language in that is should make the audience feel what is being talked about. The feeling can be termed as that of "strangeness". What this implies is that the audience is not a merely watching at a distance, but is an active player in the creation of, as well as the response to meaning in the piece of work.

Another view is brought to the definition of poetry by Anderson and Brinnin (1989, p. 874) who perceive poetry to be "a kind of rhythmic, compressed language that uses figures of speech and imagery designed to appeal to our emotions and imaginations". Rhythm is a quality not identified in the earlier definition. The latter has identified it as an element contributing to the success of poetry apart from imagery and compression, compression having already been discussed by Roberts and Jacobs. Rhythm, a quality very prevalent in music, refers to "the rise and fall of the voice produced by alternation of stressed and unstressed syllables in language". While the first definition focussed more on the forceful nature of poetry, the current one looks more on the delivery as well. This should not be taken to mean that the earlier definition does not take delivery into consideration.

The definitions of poetry here studied show that for a poem to be regarded as successful, it has to conform to certain requirements which are compression, economy, force, rhythm, and the use of figurative language and imagery to appeal to the audience's imagination and emotions. The definitions do not restrict poetry to the written artefact. They point at the fact that poetry is based on language. This means that as much as it is an artefact, it is also a product of language.

\section{Rhetoric}

Rhetoric, according to the Oxford Compact Thesaurus (2005) is associated with words and phrases such as eloquence, command, of language, way with words, and speech making. In terms of the relationship between the term and words in general, the thesaurus goes on to give words such as grandiloquence, magniloquence, and pomposity among others to be associated with it. According to Kennedy (1980), rhetoric is a theory of discourse that was developed by Greeks and Romans. Chief among these is Aristotle. He says that any definition of rhetoric that excludes Aristotle (or Cicero and Byzantium) is not very satisfactory. The definition of rhetoric, as made by Kennedy (1980), is that rhetoric is the art of persuasion.

Calder (1999) in his paper Some Operations of Dramatic Rhetoric in Richard III, I.ii, says that rhetoric, according to Aristotle is the faculty of discovering the possible means of persuasion in reference to any subject whatever. He further says that rhetoric should not be regarded as divorced from ordinary experience as the orator speaks to an expectant audience. The argument here seems to be that the audience is already aware that the speaker's intention is to persuade the audience even before the speech is delivered. 
The site http://web.cn.edu/kwheeler/resource_rhet.html says that rhetoric is the ancient art of argumentation and discourse. The site goes on to say:

When we write or speak to convince others of what we believe, we are "rhetors". When we analyze the way rhetoric works, we are "rhetoricians"... even intelligent people--can disagree with each other. Sometimes they disagree with each other about deeply held beliefs. When such disagreements become pronounced, there are two typical results--either they begin to fight, or they engage in debate. The choice is up to every country and every citizen--do we solve our problems by using a bullet or by engaging in rational discourse?... Rhetoric removes disagreement from the arena of violence and turns it into debate--a healthy and necessary step.

The site shows that rhetoric is, actually, very necessary in life. It could be suggested that, as it has already been stated above, this is the reason why rhetoric has been taught in institutions.

Finally, Aristotle (2000) himself says that rhetorical study, strictly, is concerned with the modes of persuasion. Persuasion is clearly a sort of demonstration, since we are most fully persuaded when we consider a thing to have been demonstrated. He says rhetoric, in this case, is the art of discovering all the available means of persuasion in any given case. This, he continues, is because of the rhetor's desire to achieve the intellectual and emotional effects on an audience that will persuade them to accede to the orator's point of view. This is intended to make the audience think and feel or act in a particular way.

From the few definitions given, what is most outstanding is the idea that rhetoric is anchored on persuasion. The rhetor's desire is to persuade the audience to think according to his line. Aristotle's argument could probably have been influenced by the knowledge that man is intrinsically motivated to feel that he belongs somewhere. For example, according to Maslow's Hierarchy of Needs theory, man needs to feel that he belongs somewhere. He needs to feel considered and followed. Maslow's theory can be considered to suggest that rhetors are at two of his levels; the belonging needs level and the self-esteem level (McMahon, MacMahon, \& Romano, 1995). This, it can be argued, is the reason why man has to employ rhetoric in all his dealings in life. It can be concluded hence that rhetoric is not limited to art-related fields alone but sweeps across all aspects of human interactions.

In the section following this discussion, the use of rhetoric in poetry will be examined. This will be done by essentially studying the various rhetorical devices used in poetry.

\section{The Use of Rhetoric in Poetry}

"Poetry is the records of the best and happiest moments of the happiest and best minds" so asserts Sherley (Abrams, 1999, p. 272). His argument, though not easy to substantiate, aims at maximising the belief in the impact of poetry on the audience. As it was said earlier, the poetry aims at being very forceful and hence leaving a lasting impression on the reader.

In the above definition of poetry, Sherley asserts that the minds producing poetry have to be happiest and best. The "best" would be thought in this case to mean the most brilliant, sharp, deep-thinking, cleverly-calculating, and so on. The deep mind will be accepted to be so only if it proves to us that really it is that. The idea of proving is what goes for sharing information at a much different level. This difference is present in the use of rhetorical figures or devices. These figures are meant to help in the persuasion of the audience so that, as it has already been suggested, the audience can easily be won.

The devices mentioned in this paper are mostly the commonly used ones such as the apostrophe, rhyme, 
metaphor and many others. In the discussion that follows, these devices are discussed under devices relating to semantics and those relating to sound. The discussion is largely influenced by Abrams (1999), David (2000), and Mweseli (2005) who discuss these rhetoric devices in detail.

Under devices dealing with semantics, the discussed devices include the metaphor, simile, personification, and apostrophe among others while under sound, there are devices such as rhyme, alliteration, assonance, consonance, and pun.

\section{Semantic-related Devices}

The most common figure of speech employed in poetry, is the metaphor which is one that compares objects that are very unlike without using "as", like, and so fourth. It, in fact, transfers the attributes of one object onto another. For this reason, this can be called association as opposed to comparison.

A simile, on the other hand uses like, as, and as...as for association. It is more fit to be referred to as a comparison unlike a metaphor, for reasons that have already been discussed above.

Personification is the act of giving human attributes to an inanimate being such as a stone being addressed as it were human. But, if a poet speaks to a god for assistance in his composition or art in general, it is known as invocation.

An apostrophe is a device that is used to address a person who is dead as if they were alive.

\section{Sound-related Devices}

Alliteration involves the use of a repetition of initial consonant sounds in two or more words of a line or line groups to produce a noticeable artistic device.

Rhyme is the occurrence of the same stressed vowel sounds in two words with the assumption that the accented vowel sounds involved are preceded by different consonant sounds. Rhyme comes in different varieties such as feminine rhyme, near rhyme, perfect rhyme, and masculine rhyme among others.

A repetition of similar vowel sounds in two or more words in a line or a group of lines is referred to as assonance while the repetition of consonant sounds in similar terms is referred to as consonance. Consonance should not be confused with alliteration because alliteration employs a repetition of the first consonant sounds while consonance has to do with the repetition of consonant sounds with or at the end of words in a line or group of lines.

A pun is a play on words that have similar sounds or are spelled in the same way but have different meanings.

The identified devices are employed by poets (and other literary creators) in their works to enhance meaning and appeal to their audience more. In the next section of this paper, the some of these devices are explored as employed in selected Zambian poems.

\section{Rhetoric and Meaning in Zambian Poetry}

The definition of Zambian poetry will be based more on geographical and nationality grounds. It will be assumed here that all poetry produced in Zambia and based on Zambian experiences such as can be contained in the whole idea of Zambian culture is Zambian whether produced by a Zambian or not. The paper also regards all 
works done by Zambians abroad if the works are guided by Zambian-related themes as Zambian.

For this reason, some of the works discussed will be by poets not of Zambian origin but based in Zambia and exploring Zambian-related themes in their poems. These poets include Selwyn Davis and Kwesi Sakyi. Most of the poems, of course not restricted by time and space, are by indigenous Zambians and, like those by poets not of Zambian origin, were published within the geographical boundaries of the country. The poets under this category include, in no special order, Chifumu Chipeta, Maud Muntemba, Mercy Khozi, and Gabriel Zulu. The poems will not be analysed wholly or here presented in whole. The analysis will be based on identifying and interpreting how rhetorical devices have been used. The paper will also, for purposes of this presentation analyse the use of few selected devices such as rhyme, and alliteration only with some mention of other devices in other cases.

Rhyme, it was suggested earlier, is one of the elements used in poetry. Sakyi (2009) has used rhyme in his poem Fresh Prince of Bel Air-American Legend where he says in part:

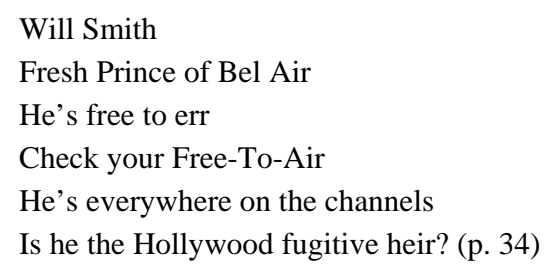

In this poem, Sakyi uses the "air" sound at the end of most lines even though "err" does not seem to fit in so well. One would even suspect that the use of "everywhere" was deliberate so that it rhymes with the other words containing the "air" sound. Obviously, the contribution made by "He's free to err" verse seems to be a bit misplaced. Could it be thought that this verse is not intended to add meaning to the poem but beauty through the use of rhyme. While the poet is very gifted with language as can be evidenced in most of his poems in both the collection from which the poem referred to comes from and his earlier work Mulungushi Sounds, the use of rhyme does not seem to be a good indicator of advancing the idea. It seems the poet in this case is more concerned with beauty rather than the idea being shared.

In Bus Stop — to Edna Juliana, Davis (1991) uses the device when in part of the poem he says:

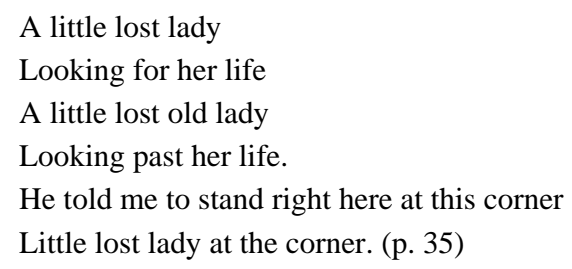

The rhyme scheme of ABABCC which is completely structured in this part of the poem is clear even though the definition earlier given questions this use of rhyme. In the definition, it was said that the assumption of rhyme is that there are different consonant sounds preceding the stressed vowel sounds of the rhyming words. In this poem obviously, the rhyme is entirely based on same words and not words of similar stressed vowel sounds.

It would be important to question whether the use of rhyme in this case is coincidental or deliberate. Even if rhyme contributes to the musicality of a poem, it does not seem to do so very well in this case as the rhythm seems to be broken in the third verse after the introduction of "old" while lost is maintained. Of course, it is not the aim of this paper to prescribe what words the poet is expected to use, the whole aim is to identify any instances of use 
of rhetorical devices and the contribution made by the same.

Khozi (2001) also uses rhyme in an almost unsatisfactory manner in her I Just Didn't Listen where she says:

I used to think that AIDS wasn't real

But now I know that it is a big deal

It is really quite a mystery

Nothing compared to misery. (p. 61)

Her use of "big deal" is very casual and very divorced from the language poets generally use. One would wonder if she merely wanted to rhyme or she really desired to say AIDS "ia a big deal”. This instance seems to suggest that rhyme can be misused in a number of cases.

A difference is seen in the use of rhyme as evidenced in Daughter of Africa by Muntemba (1991). She goes:

Go to the market and hear them swear;

Go to the bars and see them tear;

Turn to the salons and see them dye;

Turn to the roads and see them die -

Daughter of Africa: where are you going?

Turn to the roadside and see them kill;

Turn to the house and see them steal;

Go to the houses and find them sell;

Sell what - beers, food, bodies, and all -

Daughters of Africa: where are you going? (p. 92)

While the speaker seems to be addressing the daughter of Africa, the same addressee seems to be the object of these misdeeds being mentioned. Of primary concern here is the use of rhyme in this poem. For once, Muntemba convinces that she has a command of the use of rhyme even though the lines ending with the rhymes sell and all can lead to debate in terms of efficacy of the rhyme. All the same, even the use of tear gives little information in line with her information. What could she be referring to that they "tear"? While in all the other verses meaning is very easy to grasp, in this line tear becomes difficult to see. One would be made to believe that the use of tear is not merely for concealing information, as becomes the case by most poets, but also an attempt to use a word that rhymes with "swear".

One truth that cannot be denied is that the poets use of rhyme has contributed to the rhythm in the poem far more than that, the poet, by using rhyme, has even used another device, a pun, in "dye” and "die”. The use of two devices within another device is clever and demonstrates control on the part of the poet.

One notable case where rhyme has been given prominence over ideas is in a Zambian song by Che Mutale. The chorus of the song goes:

Nikamwa chibuku (When I drink chibuku)

Nimaona chipuku (I see a ghost)

Chikudya nkhuku (Eating a chicken)

Chamanga na duku (Wearing a headdress)

Nikamwa chibuku (When I drink chibuku) 
Nimaona chipuku (I see a ghost)

Chikudya nkhuku (Eating a chicken)

Chabelenga na buku (And reading a book).

In this use of rhyme, it becomes difficult to tell the poets ability to combine such devices to enhance both the aesthetic and didactic quality of the work. One is left at the crossroads as to whether the poem is intended to deliver any meaning in terms of ideas or merely to amuse the audience.

Alliteration is also used and like rhyme, contributes musical effects to the poem. In most Zambian poems, alliteration is rarely used even if it can be argued that alliteration is almost natural in most Zambian languages such as in: kamwana kang’ono kalira (a small child has cried). After a survey of most Zambian poems, very few have been seen to have alliteration. One poet who has beautifully employed the device is Chipeta (2000) in $M y$ Heart Is Closed where he says:

This heart of mine

Made of all that is tender

Soothing the tears of your time

Your heart-beat so blessing

The vibrations of tenderness

Soothing the tears of my time

You're coming close to my heart. (p. 18)

Even though alliteration is evident, it is not very pronounced. All the same, it should not be expected that alliteration should be used superfluously where the idea is even lost because of the presence of the device. In the poem above, the poet uses hard consonants like " $\mathrm{k}$ " and "t" for alliteration in "tears of time" and "coming close". While it might be expected by others that the use of hard consonants also shows the attitude towards a poem, this poem combines the had consonants with tender words like soothing and tender meanings like coming close to my heart. The alliteration in this case might be said to be a bit misplaced.

What is important still is the poet's ability to use the device in a case where, as was identified with Muntemba, other devices are also present. There is a clear use of metaphor in "soothing the tears of... time" there is also a hyperbole as the poet mentions the vibrations of tenderness. With expectations of vibrations being not as tender, from the word's use of hard consonants, the poet uses irony when he qualifies the tenderness as in vibrating hence heightening the audience's response to the poem. Indeed words synonymous with vibration are shaking, quivering, tremour, pulsating, juddering, and throbbing among others. In this instance, the poet combines devices without forgoing the idea while individual use of other devices as has been seen in alliteration gives feelings of doubt to the audience.

In his Blessed Baby, Chipopu (2002) says:

For 2000 years

In my mother's womb

I was nurtured

I struggled to come out

I waited to see dawn

To see the sun set

See the new moon

The seasons of blessing. (p. 21) 
In the few lines, Chipopu uses the "s" sound repeatedly in the entire stanza of this poem. The poem does not seem to have employed the device deliberately seeing that there probably was no other way of using language for the poet as can be noticed from the knowledge that the sun sets and we see it do so. All the same, whether coincidentally or not, the device makes a contribution and does not in any way reduce the meaning of the poem.

\section{Conclusion}

In this paper, it has been seen that Zambian poets like any other poets in the rest of the world are aware of the use of poetry for rhetorical purposes. This is substantiated by their ability to employ rhetorical devices in the poems. Of course, it could still be argued that the paper has also indicated that a number of these deliberately used devices are not used in such a way that they contribute to the message or ideas advanced by the poem. The poets in a number of cases have used these devices because they know that poetry is meant to have these devices in them.

It should be understood here that this paper has been constrained by space hence not giving a balanced study to the works and also the devices. It is hoped that an expanded version of the paper will be produced that will delve into the areas that have here been ignored regardless of the fact that they are very important.

Based on the little evidence provided, one could suggest that poets, even if well equipped with talent, can cultivate their talent by getting involved deliberately in discussions bordering on art such as literary and linguistic seminars. They could also use workshops and even formal training in university in literary composition. It could also be advisable that the teaching of literary composition, with emphasis on elements of the same, be shared with the young while they are still in school. Unlike the current situation where most get in contact with the arts through extra or is it co-) curricular activities such as drama clubs, and writers'/press clubs, the arts should be taught indiscriminately and, in fact, encouraged among the young.

\section{Areas of Further Study}

This work was restricted to the use of rhetoric in poetry and how it affects the delivery of meaning in Zambian poetry. The work cannot cover sufficiently areas such as popular music and rhetoric as in popular music there is considerable use of rhetorical devices. A study in that area would be very meaningful to scholars.

Having suggested that poetry should be taught in schools suggests that inability to compose very effectively can be blamed on the poets' lack of formal training. While formal training interferes with the art, it would still be suggested that academicians can look into the effects of formal training in the arts on artists. They could focus on how artists are advantaged and disadvantaged by formal training in the arts.

Finally, research into the effect of traditional oral composition and its effect on modern poets could help explain issues to do with expression of meaning in modern poetry. One wonders whether poets have employed the techniques depended on by traditional oral poetry composers. This is because as much as poetry in traditional circles is meant for entertainment, it is also meant for education. The role of poetry in education and how this poetry is affected by the use of stylistic devices would be well probed for an even fuller understanding of the use of rhetoric in modern Zambian poetry. 


\section{References}

Abrams, M. H. (1999). A glossary of literary terms (7th ed.). Australia: Heinle \& Heinle.

Anderson, R., \& Brinnin, J. M. (1989). Elements of literature: Fifth course. Austin: Holt, Rhinehart, and Winston, Inc.

Aristotle. (2000). Rhetoric. Retrieved December, 7, 2009, from http://classics.mit.edu/Aristotle/rhetoric.mb.txt

Calder, C. (1999). Some operations of dramatic rhetoric in Richard III, I.ii. Lusaka: University of Zambia.

Chipeta, C. (2000). My heart is closed. In Down Sunset Avenue and Other Poems. Lusaka: Multimedia Publications.

Chipopu, M. (2002). Blessed baby. In F. W. B. Akuffo (Ed.). The African renaissance local action. Lusaka: University of Zambia Development Students Association.

David, A. (2000). The Norton anthology of English literature (7th ed.). London: W. W. Norton and Company.

Davis, S. (1991). Bus stop—to Edna Juliana. In My Africa Rebirth. Lusaka: Printpark Zambia Limited.

Kennedy, G. A. (1980). Classical rhetoric and its christian and tradition from ancient to modern times. United States of America: The University of Carolina Press.

Khozi, M. (2001). I Just Didn’t Listen. In M. Nalumango (Ed.), Under the African Skies: Poetry from Zambia. Lusaka: Zambia Women Writers Association.

McMahon, F. B., MacMahon, J. W., \& Romano, T. (1995). Psychology and you. St. Paul: West Publishing Company.

Mtonga, M. (2008). Foreword. In G. M. Moyo (Ed.), Songs from my soul: Poems. Lusaka: Moffat Moyo.

Muntemba, M. (1991). Daughter of Africa. In F. Chipasula (Ed.), A decade in poetry. Lusaka: Kenneth Kaunda Foundation.

Mweseli, M. (2005). Appendix. In S. Onochie et al. (Eds.), Imagination of poets: An anthology of African poems. Port Harcourt-Agbor-Benin: Penpower Communication Co.

Roberts, E. V., \& Jacobs, H. E. (2007). Literature: An introduction to reading and writing. New Jersey: Pearson Education, Inc.

Sakyi, K. A. (2009). Fresh Prince of Bel Air-American Legend. In Mosi O Tunya Sounds: A Collection of 97 Pieces of African Poems. Lusaka: Kwesi Atta Sakyi.

Waite, M. (2005). Oxford compact thesaurus. Oxford: Oxford University Press. 